\title{
Short Communication: Effects of Nonesterified Fatty Acids on Lymphocyte Function in Dairy Heifers
}

\author{
N. Lacetera, D. Scalia, O. Franci, U. Bernabucci, \\ B. Ronchi, and A. Nardone \\ Dipartimento di Produzioni Animali, \\ Università della Tuscia, 01100, Viterbo, Italy
}

\begin{abstract}
This in vitro study was performed to assess the effects of various concentrations of nonesterified fatty acids (NEFA) on lymphocyte function of heifers. Nine Holstein heifers were studied. Peripheral blood mononuclear cells were incubated with various concentrations of NEFA (0, 0.0625, 0.125, 0.25, 0.5, 1, and $2 \mathrm{mmol} / \mathrm{L})$. The mixture of NEFA was represented by C16:0 (30\%), $\mathrm{C} 16: 1$ (5\%), C18:0 (15\%), C18:1 (45\%), and C18:2 (5\%). The DNA synthesis was diminished at concentrations of NEFA of 2,1 , and $0.5 \mathrm{mmol} / \mathrm{L}$. The IgM secretion was inhibited at concentrations of NEFA of 2, 1, 0.5, and $0.25 \mathrm{mmol} / \mathrm{L}$. Secretion of IFN- $\gamma$ was depressed at concentrations of NEFA of 2, 1, 0.5, 0.25, and 0.125 $\mathrm{mmol} / \mathrm{L}$. Increases of plasma NEFA might contribute to explain the higher incidence of infections observed in cows suffering from energy deficit.
\end{abstract}

(Key words: heifer, nonesterified fatty acid, lymphocyte function)

Abbreviation key: BrdU = 5-bromo-2'-deoxyuridine, ConA = concanavalin A, ECM = enriched culture medium, IFN- $\gamma=$ interferon- $\gamma, \mathbf{P B M C}=$ peripheral blood mononuclear cells, PHA = phytohemagglutinin, PWM = pokeweed mitogen.

Results of in vitro studies performed in the bovine to verify whether high concentrations of ketones contribute to the high incidence of infections in ketotic cows are conflicting (Targowski and Klucinski, 1983; Franklin et al., 1991; Suriyasathaporn et al., 1999). We reported immunodepression in ketotic ewes and negative relationships between immune functions and plasma NEFA or BHBA (Lacetera et al., 2001). We also found that the addition of NEFA to culture media altered sheep lymphocyte functions (Lacetera et al., 2002). The effect

Received: September 24, 2003.

Accepted: November 3, 2003.

Corresponding author: N. Lacetera; e-mail: nicgio@unitus.it. of NEFA on lymphocyte functions has not been studied before in cows.

The objective of the current in vitro study was to verify the effects of various concentrations of NEFA on DNA synthesis, IgM and interferon- $\gamma($ IFN- $\gamma)$ secretion of mitogen-stimulated peripheral blood mononuclear cells (PBMC) of cows.

Nine healthy, midpregnant Holstein heifers of approximately the same age and BW were used. Blood samples were collected via jugular venipuncture, using evacuated glass tubes coated with sodium heparin. An aliquot of blood was centrifuged to separate plasma and to determine concentrations of plasma glucose (Instrumentation Laboratory, Lexington, USA) and NEFA (Wako Fine Chemical Industries, Inc., Dallas, TX).

A NEFA mixture was made that contained a combination of C16:0 (30\%), C16:1 (5\%), C18:0 (15\%), C18:1 (45\%), and C18:2 (5\%). This mixture was prepared as described previously (Lacetera et al., 2002) by using the method of Strang et al. (1998). Briefly, a stock solution of NEFA ( $88.8 \mathrm{mM}$ ) was prepared by dissolving fatty acids in $0.1 \mathrm{~N} \mathrm{KOH}$ at a molar ratio of $1: 1.13$ at $60^{\circ} \mathrm{C}$. The NEFA-KOH solution, still at $60^{\circ} \mathrm{C}$, was neutralized by the addition of $1 \mathrm{~N} \mathrm{HCl}$ and diluted with sterile redistilled water. That solution was diluted in RPMI-1640, adjusted to $\mathrm{pH} 7.4$, and sterilized by passage through a filter. The solution was added to cell cultures in RPMI-1640 to final concentrations of 0.0625 , $0.125,0.25,0.5,1$, and $2 \mathrm{mmol} / \mathrm{L}$ of cell suspension. All reagents were purchased from Sigma (Milan, Italy). Concentrations of NEFA were designed to mimic those in healthy cows $(0.0625,0.125,0.25$, and $0.5 \mathrm{mmol} / \mathrm{L})$ and ketotic cows $(1 \mathrm{mmol} / \mathrm{L})$. The highest concentration of NEFA ( $2 \mathrm{mmol} / \mathrm{L}$ ) has instead to be considered beyond physiologic levels.

The DNA synthesis was evaluated as described (Lacetera et al., 2001). After isolation, PBMC were resuspended at a concentration of $1 \times 10^{6}$ cells $/ \mathrm{mL}$ of RPMI1640 enriched culture medium (ECM). Concentrations of NEFA and glucose in the ECM were measured and were equal to 0.006 and $9.87 \mathrm{mmol} / \mathrm{L}$, respectively. Triplicate cultures were assayed, by using 96 -well tissueculture plates. Each well contained $1 \times 10^{5} \mathrm{PBMC}$ in 
$100 \mu \mathrm{L}$ of ECM. An optimal concentration of phytohemagglutinin (PHA, $2.5 \mu \mathrm{g} / \mathrm{mL}$ ), pokeweed mitogen (PWM, $1 \mu \mathrm{g} / \mathrm{mL}$ ) or concanavalin A (ConA, $2.5 \mu \mathrm{g} / \mathrm{mL}$ ) (Sigma) was added to plates. Plates were incubated in an atmosphere of $95 \%$ air and $5 \% \mathrm{CO}_{2}$ for $48 \mathrm{~h}$ at $39^{\circ} \mathrm{C}$. We then added to wells $100 \mu M$ of 5-bromo-2'-deoxyuridine (BrdU) in $10 \mu \mathrm{L}$ of RPMI-1640, and plates were incubated for an additional $18 \mathrm{~h}$. The DNA synthesis was quantitated by an ELISA assay (Lacetera et al., 2002). The assay was performed with a commercial kit (APB, Milan, Italy) that is based on measurement of BrdU incorporated during DNA synthesis. Values for DNA synthesis were expressed as the optical density for test wells minus the optical density for control wells that did not contain BrdU. The intraassay coefficient of variation was $7.3 \%$. Secretion of IgM was established by growing PWM-stimulated cells $\left(1 \times 10^{6}\right.$ cells/well $)$ under the same conditions described above. Concentration of PWM was $0.2 \mu \mathrm{g} / \mathrm{mL}$. Cells were cultured in duplicate for $12 \mathrm{~d}$ in 24-well tissue-culture plates. At the end of the incubation, supernatants were collected and stored at $-20^{\circ} \mathrm{C}$ until analyzed. The IgM released in culture medium were quantitated by a capture ELISA (Lacetera et al., 2002). Plates were coated with a rabbitpurified antibody against bovine IgM. The IgM were detected by use of a phosphatase-conjugated sheep antibovine IgM polyclonal antibody. Antibodies were purchased from Bethyl Laboratories (Montgomery, TX). Antibody concentrations ( $\mathrm{ng} / \mathrm{mL}$ ) were calculated using a computer program (Fulvio Montauti, Pisa, Italy). The $50 \%$ absorbance values of serial dilutions of supernatant were interpolated onto the linear portion of a standard curve obtained by using purified bovine IgM (VMRD, Pullman, WA). Interassay coefficient of variation was $11.4 \%$; intraassay coefficient of variation was $2.4 \%$. Secretion of IFN- $\gamma$ was established by growing ConA-stimulated cells $\left(1 \times 10^{6}\right.$ cells/well $)$ under the same conditions described above. Cells were cultured in duplicate for $72 \mathrm{~h}$ in 24 -well tissue-culture plates. At the end of incubation, supernatants were collected and stored at $-20^{\circ} \mathrm{C}$ until analyzed. The IFN- $\gamma$ released in culture medium was quantitated by a capture ELISA, which was carried out by use of a commercial kit (CSL, Victoria, Australia). The IFN- $\gamma$ concentration (ng/mL) was established by using the same computer program utilized for IgM quantification. In this case, the standard curve was obtained by using bovine rIFN$\gamma$, which was kindly provided by Stephen Jones (CSL, Victoria, Australia). The interassay coefficient of variation was $9.6 \%$; the intraassay coefficient of variation was $5.11 \%$.

Data were reported as mean \pm SEM. Data were analyzed by a one-way ANOVA (SAS, 1996), and effects were considered to be significant at a value of $P<0.05$.
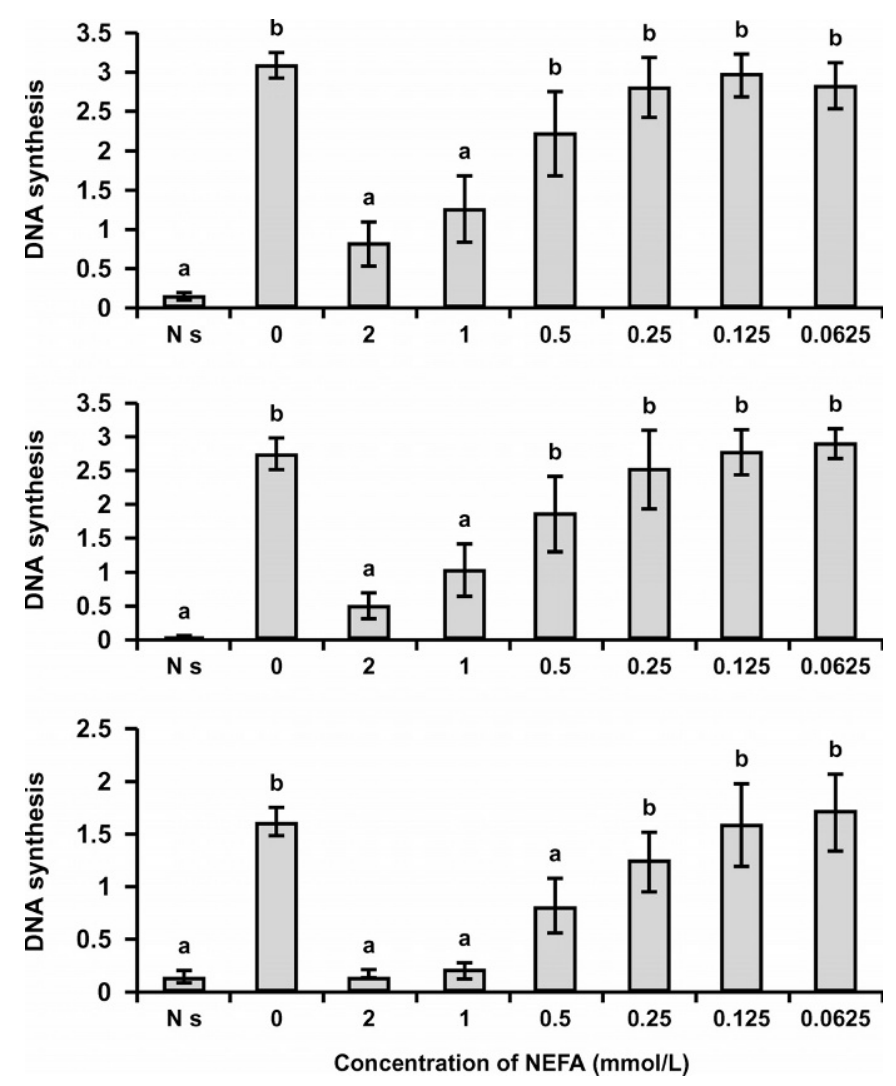

Figure 1. Effects of NEFA on DNA synthesis in peripheral blood mononuclear cells stimulated with phytohemagglutinin (top), concanavalin A (middle), and pokeweed mitogen (bottom). Values reported are mean \pm SEM of the optical density. Columns with different letters differ significantly $(P<0.01)$. Ns $=$ Not stimulated.

Values of plasma glucose and NEFA in the 9 heifers indicated a physiologic state (ranging from 3.40 and $3.64 \mathrm{mmol} / \mathrm{L}$ for glucose, and from 0.222 and 0.296 $\mathrm{mmol} / \mathrm{L}$ for NEFA).

The DNA synthesis was significantly diminished at concentrations of NEFA of 2,1 , or $0.5 \mathrm{mmol} / \mathrm{L}$ (Figure 1). The IgM secretion was inhibited at concentrations of NEFA of 2, 1, 0.5, and $0.25 \mathrm{mmol} / \mathrm{L}$ (Figure 2). Secretion of IFN- $\gamma$ was significantly depressed at concentrations of NEFA of $1,0.5,0.25$, and $0.125 \mathrm{mmol} / \mathrm{L}$ (Figure $3)$. The IFN- $\gamma$ secreted from PBMC not stimulated or cultured in the presence of $2 \mathrm{mmol} / \mathrm{L}$ of NEFA was not detectable.

Analysis of the results of the present study suggest that the increase of plasma NEFA is likely to exert negative effects on lymphocyte functions in cows. To our knowledge, the effects of NEFA on the lymphocytes functions of cows have not been tested before in vitro. Szuster-Ciesielska et al. (1995) reported a deficiency of IFN production in cows with fat mobilization syndrome. Wentink et al. (1997) documented that hepatic lipidosis 


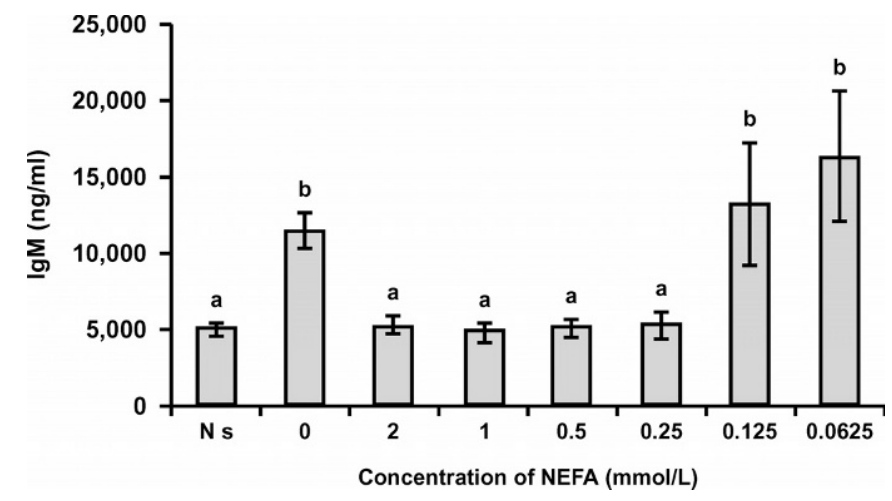

Figure 2. Effects of NEFA on IgM secretion in peripheral blood mononuclear cells stimulated with pokeweed mitogen. Values reported are mean \pm SEM. Columns with different letters differ significantly $(P<0.05)$. Ns $=$ Not stimulated.

due to intense lipomobilization is associated with impaired immunoreactivity. With regard to sheep, the addition of NEFA to PBMC cultures suppressed their ability to proliferate and secrete IgM (Lacetera et al., 2002). Compared with those results, it can be stated that cow PBMC sensitivity to NEFA seems lower compared with that of sheep. In particular, concentrations of NEFA $(0.125$ and $0.0625 \mathrm{mmol} / \mathrm{L})$ still capable of inhibiting IgM secretion in sheep PBMC ceased to exert inhibitory effects in PBMC isolated from cows. Previous in vitro bovine studies showed that the effects of ketones on PBMC vary according to glucose concentrations in the culture media (Franklin et al., 1991). Results reported herein are referred to conditions of glucose abundance in the culture media. Further in vitro studies might ascertain the response of PBMC to NEFA in conditions of limited glucose supply. Studies carried out in nonru-

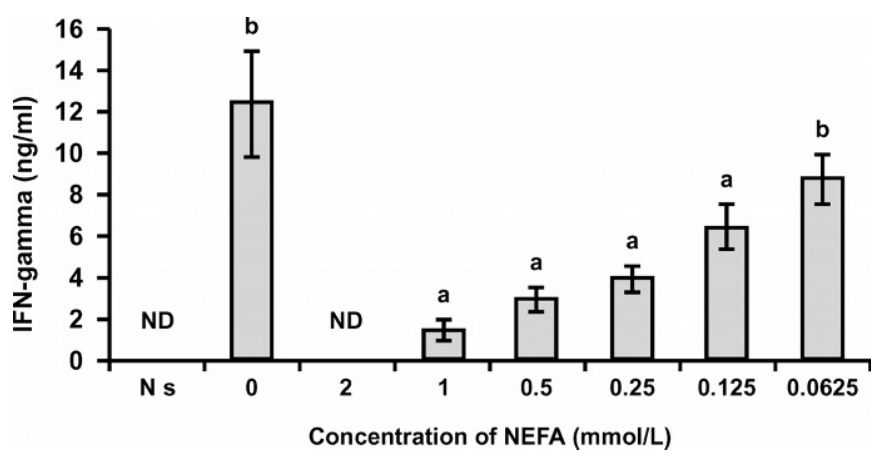

Figure 3. Effects of NEFA on interferon- $\gamma$ secretion in peripheral blood mononuclear cells stimulated with concanavalin A. Values reported are mean \pm SEM. Columns with different letters differ significantly $(P<0.01)$. Ns: not stimulated; ND: not detectable. minant species indicated numerous mechanisms through which fatty acids can modulate lymphoid cell functions. These include perturbation of properties of cellular membranes, suppression of cytokine synthesis, formation of lipid peroxides, regulation of genes, and apoptosis (De Pablo and de Cienfuegos, 2000). Results reported herein suggest that intense lipomobilization may be potentially responsible for immunodepression. The present results also indicate that plasma NEFA might represent biochemical indicators of the immune reactivity of cows. Finally, results from this experiment also represent a contribution to the studies that hypothesized high plasma NEFA as directly responsible for impairment of physiological functions of livestock suffering from energy deficit (Drackley et al., 2001; Gillund et al., 2001). In vivo studies are in progress to verify some of these hypotheses.

\section{REFERENCES}

De Pablo, M. A., and A. de Cienfuegos. 2000. Modulatory effects of dietary lipids on immune system functions. Immunol. Cell. Biol. 78:31-39.

Drackley, J. K., T. R. Overton, and G. N. Douglas. 2001. Adaptations of glucose and long-chain fatty acid metabolism in liver of dairy cows during the periparturient period. J. Dairy Sci. 84(Suppl. E):E100-E112.

Franklin, S. T., J. W. Young, and B. J. Nonnecke. 1991. Effects of ketones, acetate, butyrate and glucose on bovine lymphocyte proliferation. J. Dairy Sci. 74:2507-2514.

Gillund, P., O. Reksen, Y. T. Grhn, and K. Carlberg. 2001. Body condition related to ketosis and reproductive performance in Norwegian dairy cows. J. Dairy Sci. 84:1390-1396.

Lacetera, N., U. Bernabucci, B. Ronchi, and A. Nardone. 2001. Effects of subclinical pregnancy toxemia on immune responses in sheep. Am. J. Vet. Res. 62:1020-1024.

Lacetera, N., O. Franci, D. Scalia, U. Bernabucci, B. Ronchi, and A. Nardone. 2002. Effects of nonesterified fatty acids and (-hydroxybutyrate on functions of mononuclear cells obtained from ewes. Am. J. Vet. Res. 63:414-418.

SAS User's Guide: Statistics, Version 6.11 Edition, 1996. SAS Inst., Inc., Cary, NC.

Strang, B. D., S. J. Bertics, R. R. Grummer, and L. E. Armentano. 1998. Effect of long-chain fatty acids on triglyceride accumulation, gluconeogenesis, and ureagenesis in bovine hepatocytes. J. Dairy Sci. 81:728-739.

Suriyasathaporn, W., A. J. J. M. Daemen, E. N. Noordhuizen-Stassen, S. J. Dieleman, M. Nielen, and Y. H. Schukken. 1999. $\beta$-Hydroxybutyrate levels in peripheral blood and ketone bodies supplemented in culture media affect the in vitro chemotaxis of bovine leukocytes. Vet. Immunol. Immunopathol. 68:177-186.

Szuster-Ciesielska, A., J. Filar, and M. Kandefer-Szerszen. 1995. Depression of interferon production in leukocytes of cows with fat mobilization syndrome. Arch. Immunol. Ther. Exp. 43:61-65.

Targowski, S. P., and W. Klucinski. 1983. Reduction in mitogenic response of bovine lymphocytes by ketone bodies. Am. J. Vet. Res. 44:828-830.

Wentink, G. H., V. P. M. Rutten, T. S. van den Ingh, A. Hoek, K. E. Mller, and T. Wensing. 1997. Impaired specific immunoreactivity in cows with hepatic lipidosis. Vet. Immunol. Immunopathol. $56: 77-83$. 